\title{
Histomorphometric study of the effect of methionine on small intestine parameters in rat: an applied histologic study
}

\author{
S. Seyyedin ${ }^{1}$, M.N. Nazem² \\ Shahid Bahonar University of Kerman, Kerman, Iran \\ [Received: 26 January 2017; Accepted: 11 April 2017]
}

\begin{abstract}
Background: Assessment of morphological changes has more often been used in the diagnosis and assessment of intestinal pathology and development. Since methionine is widely used in nutritional and sports supplements and also there is not enough information about the effect of this amino acid on the gastrointestinal histomorphometry, the aim of this study was to assess the effect of methionine on the small intestine histomorphometry.

Materials and methods: Thirty male Wistar rats were randomly divided to three equal groups. Two treatment groups received 100 and $200 \mathrm{mg} / \mathrm{kg}$ L-methionine solution respectively via intraperitoneal injection while the control group received normal saline. On day 21, all rats were euthanised and segments from three parts of small intestine were taken to histomorphometrical study. Paraffin sections were stained with haematoxylin and eosin, alcian blue (AB) and periodic acid Schiff (PAS) methods separately. In order to analyse histomorphometric features of each segment, villus height, width, area, crypt depth, villus height to crypt depth ratio, goblet cell number, and muscle layer thickness were measured.

Results and Conclusions: Obtained results revealed that methionine may change the histomorphometric parameters of small intestine. (Folia Morphol 2017; 76, 4: 620-629)
\end{abstract}

Key words: histomorphometry, small intestine, methionine, rat

\section{INTRODUCTION}

The small intestine is the long muscular tube of the gastrointestinal tract that is the major site for absorption and digestion of nutrients and drugs. It is made up of three structural segments: duodenum, jejunum and ileum [17-19]. All of the absorptive and also a part of the digestive capacity of the small intestine occur around and near villi and crypts [21]. Actually the crypt-villus is the main functional unit of absorption in the rat's small intestine. Various substances and also different physiological or pathological conditions may change the proliferation rate of enterocytes in the crypt and affect their migration rate to the top of the villi [46]. The relation between small intestine and nutritional factors is very complicated. Nutrients may directly cause changes or adaptations in the intestinal mucosa $[4,47]$.

Methionine (Met), a sulphur-containing essential amino acid, serves as the initiating amino acid in the synthesis of many proteins. It plays an important role in the synthesis of vital molecules such as cysteine, carnitine, taurine, lecithin, phosphotidyl choline and

Address for correspondence: M.N. Nazem, Associate Professor of Anatomy, Histology and Embryology, Department of Basic Sciences, School of Veterinary Medicine, Shahid Bahonar University of Kerman, Pazhuhesh Square, Kerman, Iran. P.0. Box: 76169133, tel: +983431322954, fax: +983433257447, e-mail: nnazem@uk.ac.ir; nasernazem@yahoo.com 
other phospholipids. It has a significant effect on improving cartilage formation and is therefore used in arthritis treatment [49].

Histomorphometric analysis is greatly used in studies about gastrointestinal pathophysiology. The availability of animal models and using morphometric analysis as a quantitative assessment have facilitated evaluating the morphological alterations of intestinal mucosa under various experimental conditions such as special diets and drugs [10].

The laboratory rat, as an animal model, has been used in several histological and histomorphometrical studies $[1,53]$. Some of these studies have described the qualitative and quantitative changes that occur in the small intestine under various physiological and pathological conditions [10, 11, 13, 31, 32]. Many studies have investigated the effect of methionine supplementation on the skin [30], teeth [25], liver disorders [23], feather follicles [28], female reproductive system $[3,29]$ and neural tube in the embryos [24] but there is not enough information about its effect on the small intestine in the mammals.

Methionine is widely used in nutritional and sports supplements and on the other hand the effects of these supplements have not been investigated on the gastrointestinal histomorphometry. So the aim of this study was to assess the effect of injected methionine on histomorphometric aspects of small intestine in the rat.

\section{MATERIALS AND METHODS}

The experiment in this study was approved by the Animal Ethics Committee, a branch of the Research Council of the Veterinary School in Shahid Bahonar University, Kerman Province, Iran.

A total of thirty male Wistar rats weighing 190$-210 \mathrm{~g}$ were used for this research. The rats were housed in clean plastic cages and kept under the following conditions: $12 \mathrm{~h}$ light/dark cycle, controlled temperature of $22-25^{\circ} \mathrm{C}$ and humidity of $60-70 \%$. The rats were allowed an adaptation period of 5 days with free access to commercial rodent diet and water ad libitum. The rats were randomly divided into three groups containing ten rats. All three groups received intraperitoneal injections for 20 consecutive days. Rats in the group A served as the control group and were administered with normal saline. Group B and C rats were treated with L-methionine (Merck, Germany) $100 \mathrm{mg} / \mathrm{kg}$ and $200 \mathrm{mg} / \mathrm{kg}$ body weight, respectively. Dose regimen, duration and route of administra- tion in this study were based on a previous research that investigated the histomorphometric effect of methionine on the rat's skin [30]. At the end of the treatment period, all rats were euthanised. The abdomen was opened through a midline incision and the small intestine of each rat was gently removed. Then small segments of intestine, about $1 \mathrm{~cm}$ in size, were removed from the duodenum (below the pyloro-duodenal junction), jejunum ( $2 \mathrm{~cm}$ anterior to Meckel's diverticulum) and ileum ( $2 \mathrm{~cm}$ anterior to ileocecal junction). All intestinal portions were fixed in $10 \%$ neutral buffered formalin for 10 days $[4,36]$, dehydrated in graded anhydrous absolute ethanol and xylol, embedded in paraffin blocks and then cut into $5 \mu \mathrm{m}$ sections. In each animal, one section that represented the best view of villus and crypts was selected to be analysed. The sections were stained using haematoxylin and eosin (H\&E) (for standard histological evaluation), periodic acid Schiff (PAS) (in order to count the number of neutral goblet cells) and alcian blue (AB) (in order to count the number of acidic goblet cells) techniques. Slides were examined using an Olympus light microscope and photomicrographs were taken by an attached eyepiece camera (Dino-eye, AM-7023, 5Mp, Taiwan). The following intestinal histomorphometric parameters were evaluated in all sections stained with H\&E method: villous height, villous width, crypt depth and the muscular layer thickness. These parameters were measured on 20 well-aligned villi and corresponding crypts from each section of all intestinal segments. The heights of the villi were defined from their tip to the base and the widths were measured at the half height point. Calculations using villous height and width at half height gave the villus surface area. The depth of intestinal crypts was measured as the distance from top of villus crypt to muscularis mucosa.

The number of goblet cells per villus was counted in ten well-oriented and adjacent crypt villus on each section stained by PAS and AB histochemical techniques. All measurements were made in $\mu \mathrm{m}$, at $\times 100$ magnification.

\section{Statistical analysis}

Results were expressed as mean values \pm standard error. Data were analysed using one-way analysis of variance (ANOVA) followed by post hoc, Tukey's HSD test. Statistical analysis was performed using SPSS (SPSS for Windows, version 16.0, SPSS Inc., Chicago, Illinois). Differences were considered statistically significant when the calculated $p$ value was less than 0.05 . 
Table 1. The effect of intraperitoneal administration of methionine on the histomorphometric parameters of rat duodenum (values are mean \pm standard error)

\begin{tabular}{lccc}
\hline & Control & Met 100 & Met 200 \\
\hline VH $[\mu \mathrm{m}]$ & $389.47 \pm 33.84^{\mathrm{a}}$ & $533.84 \pm 23.05^{\mathrm{b}}$ & $525.82 \pm 14.61^{\mathrm{b}}$ \\
$\mathrm{WW}[\mu \mathrm{m}]$ & $69.47 \pm 5.58^{\mathrm{a}}$ & $103.22 \pm 6.41^{\mathrm{b}}$ & $106.66 \pm 6.56^{\mathrm{b}}$ \\
VA $\left[\mu \mathrm{m}^{2}\right]$ & $27056.65 \pm 2350.8^{\mathrm{a}}$ & $55102.96 \pm 2379.22^{\mathrm{b}}$ & $56084.15 \pm 1557.7^{\mathrm{b}}$ \\
$\mathrm{CD}[\mu \mathrm{m}]$ & $264.28 \pm 13.74^{\mathrm{a}}$ & $264.32 \pm 32.31^{\mathrm{a}}$ & $166.72 \pm 9.79^{\mathrm{b}}$ \\
VH/CD & $1.47 \pm 0.13^{\mathrm{a}}$ & $2.01 \pm 0.09^{\mathrm{b}}$ & $3.15 \pm 0.09^{\mathrm{c}}$ \\
Goblet cells (AB) & $8.67 \pm 1.05^{\mathrm{a}}$ & $15.83 \pm 1.89^{\mathrm{b}}$ & $12.57 \pm 2.01^{\mathrm{ab}}$ \\
Goblet cells (PAS) & $8.9 \pm 0.86^{\mathrm{a}}$ & $16.11 \pm 1.43^{\mathrm{b}}$ & $12.13 \pm 1.11^{\mathrm{ab}}$ \\
Muscle layer thickness $[\mu \mathrm{m}]$ & $77.94 \pm 5.38^{\mathrm{a}}$ & $101.26 \pm 8.49^{\mathrm{b}}$ & $157.17 \pm 6.99^{\mathrm{c}}$ \\
\hline
\end{tabular}

$a, b, c$ Means in the same row with no common superscript differ $(p<0.05)$.

$A B$ - alcian blue; $C D$ - crypt depth; PAS — periodic acid Schiff; VA — villus area; VH — villus height; VW — villus width

Table 2. The effect of intraperitoneal administration of methionine on the histomorphometric parameters of rat jejunum (values are mean \pm standard error)

\begin{tabular}{lccc}
\hline & Control & Met 100 & Met 200 \\
\hline VH $[\mu \mathrm{m}]$ & $353.04 \pm 10.64^{\mathrm{a}}$ & $405.53 \pm 8.8^{\mathrm{b}}$ & $423.16 \pm 16.05^{\mathrm{b}}$ \\
$\mathrm{WW}[\mu \mathrm{m}]$ & $87.26 \pm 5.78^{\mathrm{a}}$ & $120.72 \pm 2.79^{\mathrm{b}}$ & $107.24 \pm 5.54^{\mathrm{b}}$ \\
$\mathrm{VA}\left[\mu \mathrm{m}^{2}\right]$ & $30406.09 \pm 1101.46^{\mathrm{a}}$ & $38287.1 \pm 1782.05^{\mathrm{b}}$ & $45380.1 \pm 1721.66^{\mathrm{c}}$ \\
$\mathrm{CD}[\mu \mathrm{m}]$ & $214.61 \pm 7.19^{\mathrm{a}}$ & $208.15 \pm 6.07^{\mathrm{a}}$ & $161.86 \pm 10.64^{\mathrm{b}}$ \\
$\mathrm{VH} / \mathrm{CD}$ & $1.64 \pm 0.05^{\mathrm{a}}$ & $1.52 \pm 0.07^{\mathrm{a}}$ & $2.61 \pm 0.1^{\mathrm{b}}$ \\
Goblet cells (AB) & $12 \pm 1.21^{\mathrm{a}}$ & $20 \pm 1.37^{\mathrm{b}}$ & $18.6 \pm 1.63^{\mathrm{b}}$ \\
Goblet cells (PAS) & $14 \pm 1.31^{\mathrm{a}}$ & $23.2 \pm 1.88^{\mathrm{b}}$ & $19.8 \pm 0.86^{\mathrm{b}}$ \\
Muscle layer thickness $[\mu \mathrm{m}]$ & $61.33 \pm 5.12^{\mathrm{a}}$ & $81.35 \pm 5.01^{\mathrm{b}}$ & $88.06 \pm 6.09^{\mathrm{b}}$ \\
\hline
\end{tabular}

$a, b, c$ Means in the same column with no common superscript differ $(p<0.05)$.

$\mathrm{AB}$ - alcian blue; $\mathrm{CD}$ — crypt depth; PAS — periodic acid Schiff; VA — villus area; VH — villus height; VW — villus width

Table 3. The effect of intraperitoneal administration of methionine on the histomorphometric parameters of rat ileum (values are mean \pm standard error)

\begin{tabular}{lccc}
\hline & Control & Met 100 & Met 200 \\
\hline VH $[\mu \mathrm{m}]$ & $199.47 \pm 5.11^{\mathrm{a}}$ & $272.2 \pm 7.46^{\mathrm{b}}$ & $265.56 \pm 2.78^{\mathrm{b}}$ \\
$\mathrm{WW}[\mu \mathrm{m}]$ & $94.53 \pm 2.51^{\mathrm{a}}$ & $130.73 \pm 3.15^{\mathrm{b}}$ & $118.58 \pm 4.5^{\mathrm{b}}$ \\
$\mathrm{VA}\left[\mu \mathrm{m}^{2}\right]$ & $18856.89 \pm 482.22^{\mathrm{a}}$ & $33811.26 \pm 2356.84^{\mathrm{b}}$ & $31490.1 \pm 329.83^{\mathrm{b}}$ \\
$\mathrm{CD}[\mu \mathrm{m}]$ & $221.72 \pm 5.01^{\mathrm{a}}$ & $186.87 \pm 3.66^{\mathrm{b}}$ & $206.68 \pm 0.73^{\mathrm{a}}$ \\
$\mathrm{VH} / \mathrm{CD}$ & $0.9 \pm 0.02^{\mathrm{a}}$ & $1.45 \pm 0.04^{\mathrm{b}}$ & $1.28 \pm 0.01^{\mathrm{c}}$ \\
Goblet cells (AB) & $19.8 \pm 2.08^{\mathrm{a}}$ & $27.67 \pm 1.48^{\mathrm{b}}$ & $25 \pm 1.63^{\mathrm{ab}}$ \\
Goblet cells (PAS) & $24.86 \pm 1.35^{\mathrm{a}}$ & $31 \pm 1.68^{\mathrm{b}}$ & $24.56 \pm 1.55^{\mathrm{a}}$ \\
Muscle layer thickness $[\mu \mathrm{m}]$ & $55.13 \pm 4.54^{\mathrm{a}}$ & $66.85 \pm 3.94^{\mathrm{b}}$ & $72.66 \pm 4.15^{\mathrm{b}}$ \\
\hline
\end{tabular}

$a, b, c$ Means in the same column with no common superscript differ ( $p<0.05)$.

$\mathrm{AB}$ - alcian blue; $\mathrm{CD}$ — crypt depth; PAS — periodic acid Schiff; VA — villus area; VH — villus height; VW — villus width

\section{RESULTS}

According to our findings, the villus height and width in the duodenum (Table 1, Fig. 1) jejunum
(Table 2, Fig. 2) and ileum (Table 3, Fig. 3) were significantly increased in both treatment groups compared with controls $(p<0.05)$. However, there was not any 

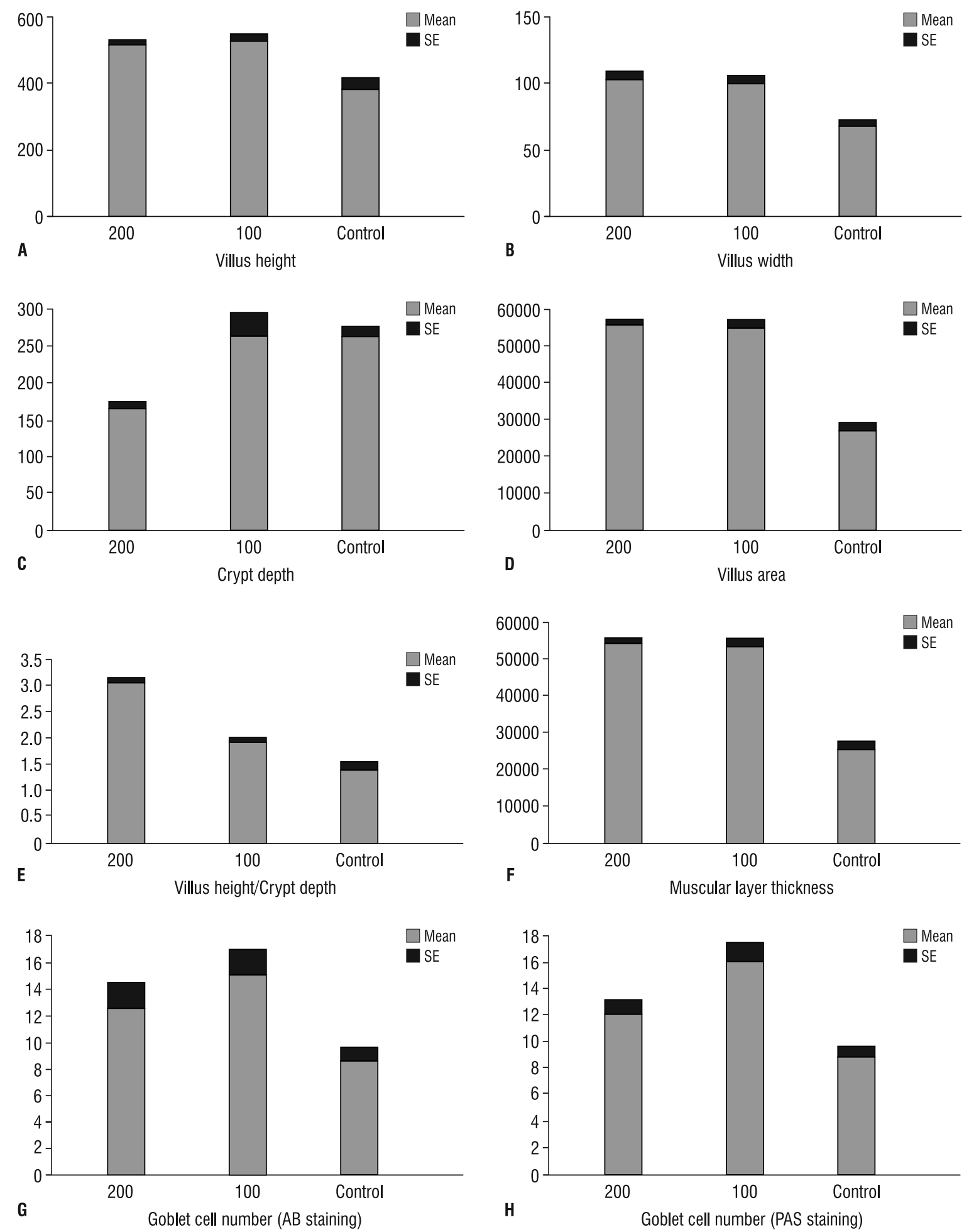

Figure 1. Histomorphometric measurements of the duodenum of control (Control) and treatment groups: 100 (Met 100) and 200 (Met 200). Bars are mean \pm standard error (SE). The unit of villus height, villus width, crypt depth and muscular layer thickness is $\mu \mathrm{m}$. The unit of villus area is $\mu \mathrm{m}^{2}$; A. Villus height; B. Villus width; C. Crypt depth; D. Villus area; E. Villus height/crypt depth; F. Muscular layer thickness; G. Goblet cell number (AB staining); H. Goblet cell number (PAS staining).

significant difference between treatment groups in all intestinal segments (Tables 1-3). It was observed that in all small intestine portions, the groups treated with methionine showed significant increase in villus area compared with the control groups $(p<0.05)$. It was noticeable that the difference in the villus area 

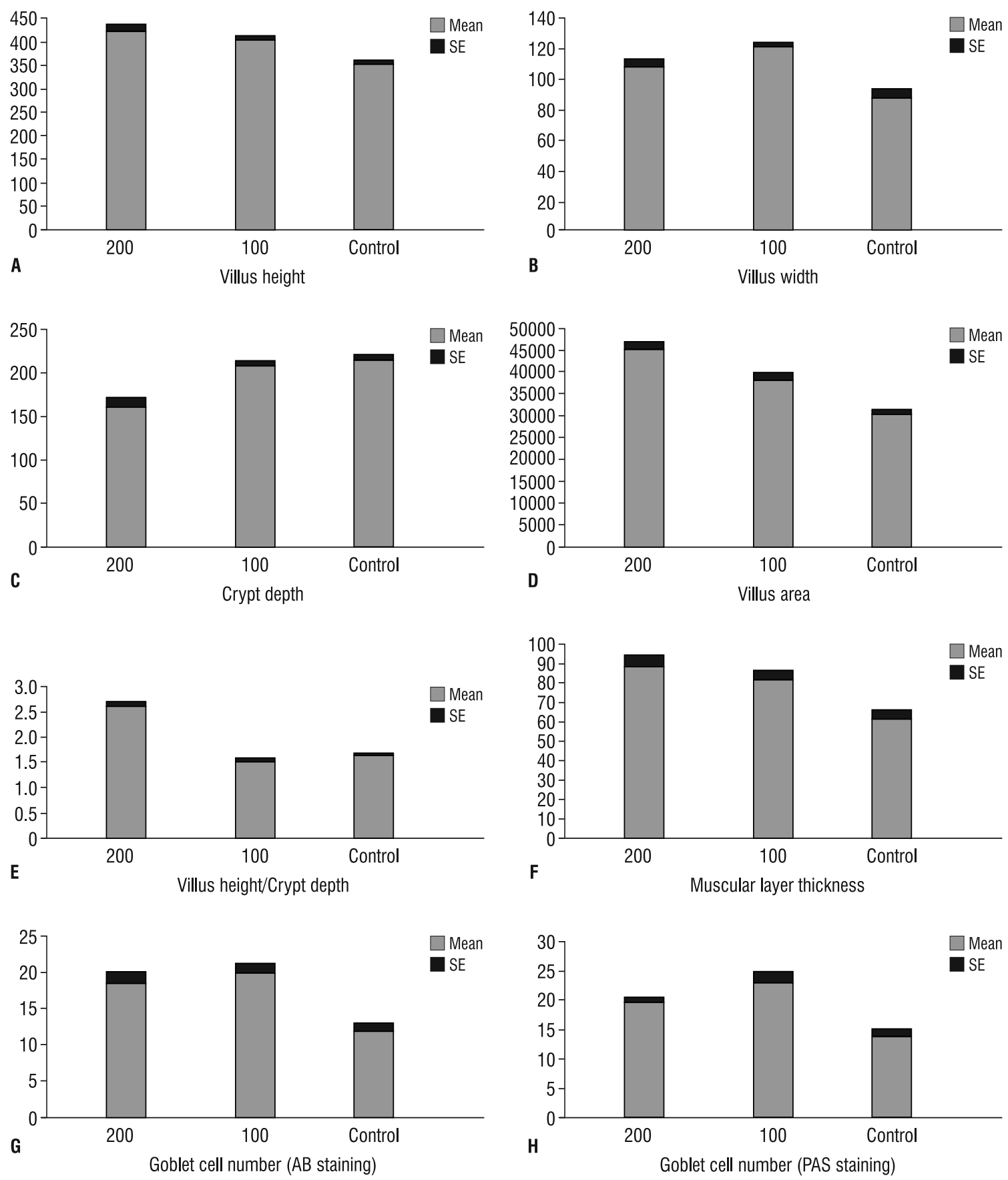

Figure 2. Histomorphometric measurements of the jejunum of control (Control) and treatment groups: 100 (Met 100) and 200 (Met 200). Bars are mean \pm standard error (SE). The unit of villus height, villus width, crypt depth and muscular layer thickness is $\mu \mathrm{m}$. The unit of villus area is $\mu \mathrm{m} 2 ;$ A. Villus height; B. Villus width; C. Crypt depth; D. Villus area; E. Villus height/crypt depth; F. Muscular layer thickness; G. Goblet cell number (AB staining); $\mathbf{H}$. Goblet cell number (PAS staining).

in the jejunum was significant between two treatment groups (Fig. 2, Table 2). The results of this study showed that the depth of the crypts in duodenum and jejunum were significantly decreased in the Met 200 group as compared to both Met 100 and control groups $(p<0.05)$, but there was no significant difference between the Met 100 and control groups.
However in the ileum, the depth of the crypts of Met 100 group were decreased compared to the other groups $(p<0.05)$ (Fig. 4; Tables 1-3).

On histological observation, in the duodenum, significantly increased villus height to crypt depth ratio was observed in methionine treated groups as compared to the control group $(p<0.05)$. It should 

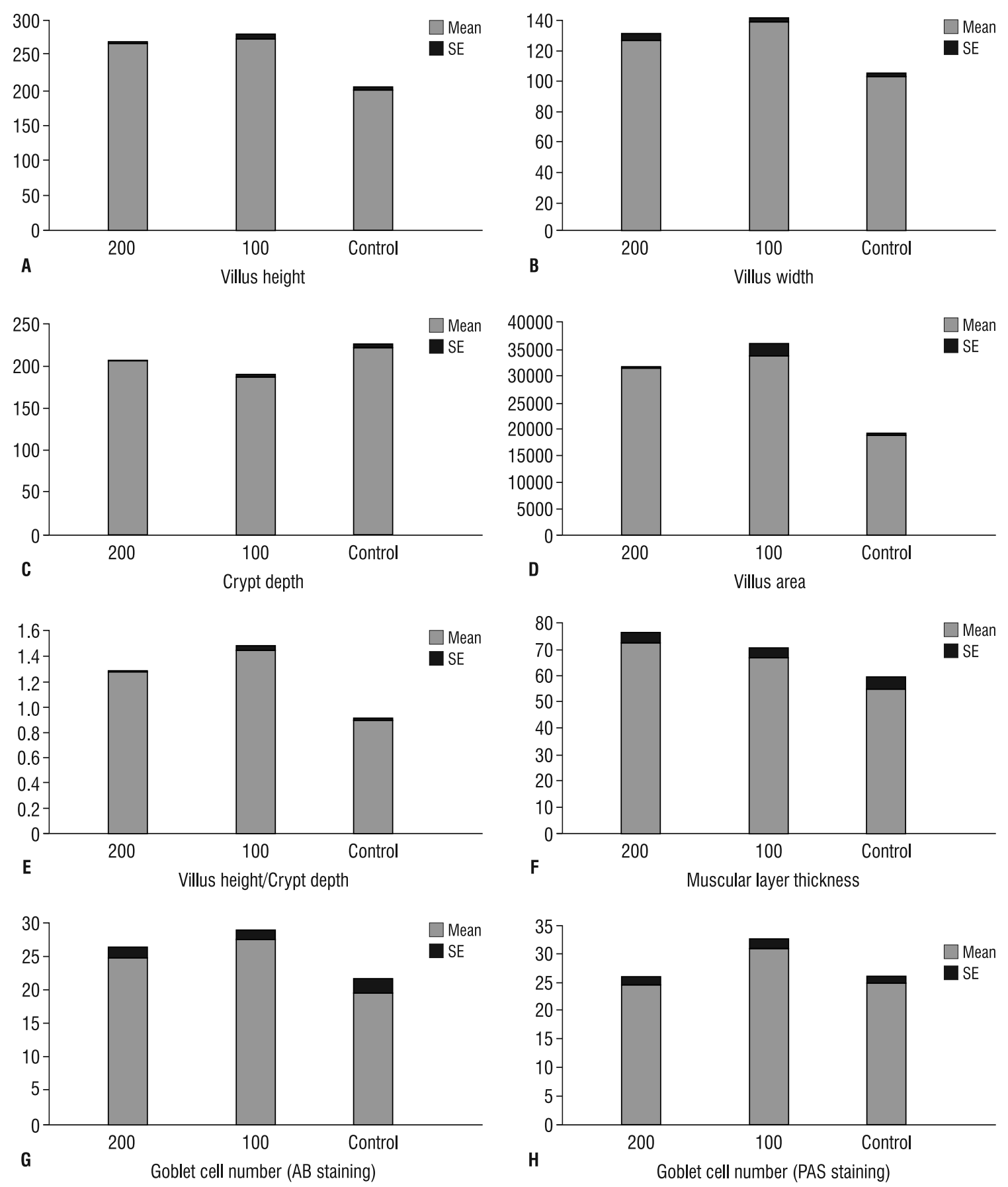

Figure 3. Histomorphometric measurements of the ileum of control (Control) and treatment groups: 100 (Met 100) and 200 (Met 200). Bars are mean \pm standard error (SE). The unit of villus height, villus width, crypt depth and muscular layer thickness is $\mu \mathrm{m}$. The unit of villus area is $\mu \mathrm{m}^{2}$; A. Villus height; B. Villus width; C. Crypt depth; D. Villus area; E. Villus height/crypt depth; F. Muscular layer thickness; G. Goblet cell number (AB staining); $\mathbf{H}$. Goblet cell number (PAS staining).

also be noted that a significant increase in villus height to crypt depth ratio was observed in the Met 200 group compared to Met 100 group (Table 1). In the jejunum, this ratio was greater in the Met 200 group compared with the other groups $(p<0.05)$. No significant difference was observed the Met 100 and the control groups (Table 2). In the ileum, the villus height to crypt depth ratio was significantly increased in treatment groups compared to the control group and also the villus height to crypt depth ratio was greater in Met 100 group compared with Met 200 group (Table 3). 


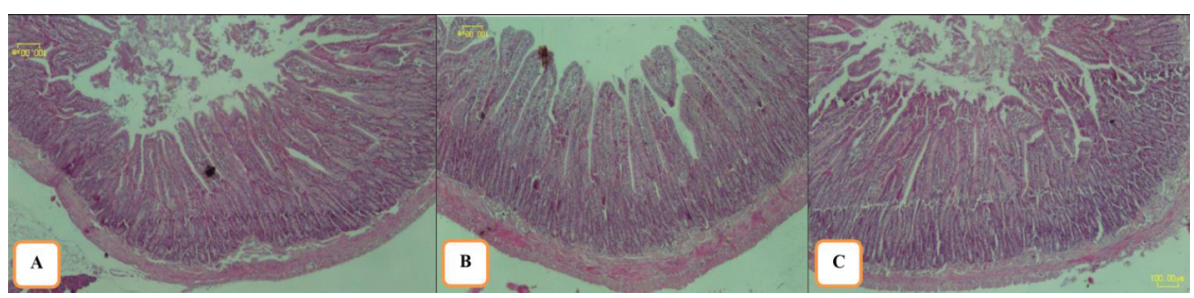

Figure 4. Histological features of the jejunum of control (A), Met 100 (B) and Met 200 (C) groups. Based on these figures, villi heigh and width in both Met 100 and Met 200 are increased compare to the control group; haematoxylin and eosin (H\&E); 40X.

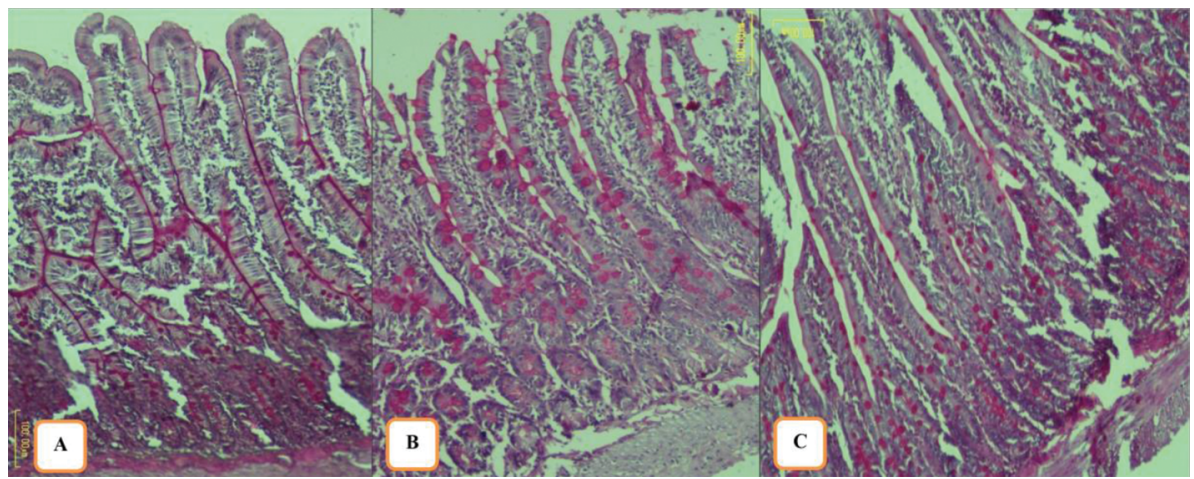

Figure 5. Periodic acid Schiff (PAS) staining of the jejunum of control (A), Met 100 (B) and Met 200 (C) groups. The greatest number of PAS-positive goblet cells are visible in the Met 100 group (B); PAS; 40X.

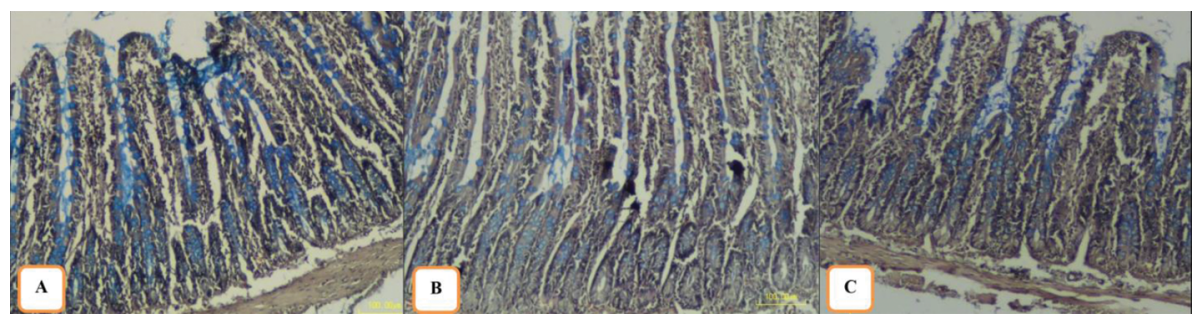

Figure 6. Alcian blue (AB) staining shows an increase in the acidic goblet cells of the jejunum of control (A), Met 100 (B) and Met 200 (C) groups. The greatest number of AB-positive goblet cells are visible in the Met 200 group (C); $A B ; 40 \times$.

In all small intestine segments, the thickness of the muscular layer was greater in the methionine treated groups than in the controls $(p<0.05)$. Also, in the duodenum the Met 200 groups had thicker muscular layer compared with the Met 100 group $(p<0.05)$ (Tables 1-3).

In the duodenum, jejunum and ileum the count of goblet cells that were stained by AB and PAS methods, showed a growth in the treatment groups compared to controls. In all small intestine parts, goblet cells in the Met 100 group were more numerous than in the other groups and this increase was significant in comparison with the control groups $(p<0.05)$ (Figs. 5,6$)$.

All data are shown in Tables 1-3 and Figures 1-3.

\section{DISCUSSION}

The morphology of small intestine is considered as the main indicator of normal gut histology [22]. Absorption of nutrients and drugs is facilitated through the enormous surface area available in this organ [18]. A part of the functional status of the small intestine is defined by villus height and crypt depth [22]. The villi and crypts of the absorptive epithelium play an important role in the final stage of nutrient digestion and assimilation [54]. Alterations in intestinal morphology may affect nutrient metabolisability and performance [22]. For instance, an increase in villi height may result in a growth in total luminal villus absorptive area and leads to satisfactory digestive 
enzyme action and higher transport of nutrients at the villus surface [48].

The development of small intestine can be evaluated through measurements of the crypt depth, villus height and surface area to define the available area for digestion and absorption [9, 44].

Nowadays methionine supplements are widely used for the treatment of some skin and hair diseases [45], arthritis [49], tooth growth [25] and also protect the kidney from some drugs' nephrotoxicity [5]. Due to the important side effects of methionine [29, 35, $37,38]$, the consumption of this amino acid must be under controlled conditions. This is the first study to investigate the effect of different methionine dosages on the histomorphometric parameters of the small intestine of rat. Also to the authors' knowledge, there have been no studies done on the effects of amino acids on the histology and morphology of the rat's small intestine.

Based on the results of this study, administration of methionine caused an increase in villus height, villus width and finally villus area of all intestinal segments. It has been suggested that increased villi height is correlated with improved normal gut histology and may increase performance by improving nutrient absorption $[2,50]$. The measurement of the villus area correlates very well with the total number of epithelial cells in the villus [12]. Therefore, it seems that following the injection of methionine could lead to an increase in digestion and absorption of the nutrients in all small intestine parts. The duodenum has the major role in nutrient absorption and the decrease in villi size from the duodenum to ileum is due to the lower absorptive capacity in the last portion of small intestine [41]. This is consistent with our findings in this study that showed the villi height in the duodenum was greater than those in the jejunum and ileum. It is also noticeable that the villi width was increased from the duodenum, through the jejunum to the ileum. Depth of the crypts was decreased in methionine treated rats compared to the controls. However, the crypt depth of the duodenum in the Met 100 group was not decreased as compared to the control group. Kelly et al. [20] reported that decrease in the crypt depth caused an increase in the enzymatic activity of the small intestine of pigs. So we suggest that methionine supplementation may increase the intestinal digestion activity. Following the administration of methionine, the ratio of villus height to crypt depth was increased. This parameter was not increased in the jejunum of Met 100 group compared to the control group. A higher villus height to crypt depth ratio results in a decreased turnover of the intestinal mucosa. A slower turnover rate of the intestinal epithelium leads to a lower maintenance requirement and finally can result in a higher growth efficiency of the animal [52]. Overall it can be said that villus height, crypt depth and the ratio of villus height to crypt depth are considered as a criterion to reflect the small intestine morphology and absorption capacity [27]. Therefore, an increase in villus height, villus height to crypt depth ratio or decrease in the crypt depth is correlated with an improvement in the digestion and absorption of nutrients [14-16, 55].

Villus height to crypt depth ratio is one of the most important histomorphometric parameters of the small intestine. Based on the obtained results in the duodenum and jejunum, the villus height to crypt depth ratio was significantly increased in Met 200 group compared to Met 100 group. Since the duodenum and jejunum are the most important absorptive parts of the small intestine, it may be concluded that the $200 \mathrm{mg} / \mathrm{kg}$ dosage of methionine has a better effect on the absorption of the nutrients than the $100 \mathrm{mg} / \mathrm{kg}$ dosage. So it can be interpreted that $200 \mathrm{mg} / \mathrm{kg}$ dosage does not have toxic effects on the small intestine. This finding is in contrast with a previous study conducted by Nazem et al. [29] which showed that $200 \mathrm{mg} / \mathrm{kg}$ methionine has more toxic effects than $100 \mathrm{mg} / \mathrm{kg}$ dosage in rat's uterus.

Unlike the obtained results in duodenum and jejunum, the villus height to crypt depth ratio was greater in Met 100 compare to Met 200 in the ileum. It may be due to an imbalance in amount of amino acids in this small intestine part. The similar pattern between the histomorphometry of the ileum and the two other parts of small intestine was also reported in the pregnant rats [36].

The epithelial cells of the small intestine are covered by a protective mucus blanket composed of high molecular weight glycoproteins known as mucins [34]. Mucins which are synthesised and secreted from goblet cells act as the first line of defence against intestinal pathogens and play a significant role in the maintenance of mucosal homeostasis $[6,26,43]$. The mucus layer acts as a medium in which digestion and absorption processes happen close to the brush-border membrane [42]. Several studies have reported the modulation of goblet cell number and 
mucin secretion under different conditions such as varied diet, surgery and altered microbiota $[7,33$, $39,40,51]$. Obtained results in our study showed that in all intestinal segments, the number of goblet cells that were stained by PAS and AB methods were increased in methionine treated rats compared to controls, which may be indicative of an increase in mucin secretion. The increase in mucin secretion may favour movement of the digesta [8]. Also any changes in the thickness of the mucus layer may influence nutrient digestibility processes [42]. So it seems that administration of methionine may affect digestion by an increase in mucin secretion in the small intestine.

Muscular layer thickness was also increased after methionine administration. A previous study conducted by Sabet Sarvestani et al. [36] showed that the duodenum has gained more capacity to digest food intake during pregnancy by increasing villi length and muscular layer thickness. A positive effect of methionine supplementation on skeletal muscle growth has been also reported in the chickens [45]. In this study, the tunica muscularis was thicker in all intestinal segments in methionine treated rats, which may increase the contact between the intestinal content and the mucosa. We proposed that methionine may have a positive effect on the growth of the tunica muscularis layer and therefore improves digestion.

\section{CONCLUSIONS}

In conclusion we have shown that administration of methionine as the first limiting amino acid may affect the digestion and absorption of nutrients in all small intestine segments by an increase in villi length, villi width, villi area, number of goblet cells and finally the muscular layer thickness. Although injection of methionine caused an alteration in small intestine histomorphometric parameters, defining the optimal dose of methionine in rat needs further studies. It is noticeable that there is not a direct relation between increased methionine dosages and their effects on some tissues in rats [30].

\section{Acknowledgements}

This research was financially supported by a grant (No: 1/5/1395) from the Technology and Research Council of Shahid Bahonar University of Kerman, Iran. The authors would like to thank Mr. Mazhab Jafari for providing histological laboratory methods and histology slides.

\section{REFERENCES}

1. Al-Qudah MM. Histological effects of aging on male albino rats duodenum. World J Med Sci. 2014; 10: 174-178.

2. Baurhoo B, Phillip L, Ruiz-Feria CA. Effects of purified lignin and mannan oligosaccharides on intestinal integrity and microbial populations in the ceca and litter of broiler chickens. Poult Sci. 2007; 86(6): 1070-1078, indexed in Pubmed: 17495075.

3. Berker B, Kaya C, Aytac R, et al. Homocysteine concentrations in follicular fluid are associated with poor oocyte and embryo qualities in polycystic ovary syndrome patients undergoing assisted reproduction. Hum Reprod. 2009; 24(9): 2293-2302, doi: 10.1093/ humrep/dep069, indexed in Pubmed: 19443458.

4. Caruso M, Demonte A, Neves VA. Histomorphometric study of role of lactoferrin in atrophy of the intestinal mucosa of rats. Health. 2012; 04(12): 1362-1370, doi: 10.4236/health.2012.412198.

5. Derakhshanfar A, Bidadkosh A, Hashempour Sadeghian M. L-methionine attenuates gentamicin nephrotoxicity in male Wistar rat: pathological and biochemical findings. IJVR. 2009; 10(4): 323-328.

6. Dharmani P, Srivastava V, Kissoon-Singh V, et al. Role of intestinal mucins in innate host defense mechanisms against pathogens. J Innate Immun. 2009; 1(2): 123-135, doi: 10.1159/000163037, indexed in Pubmed: 20375571.

7. Dunsford BR, Haensly WE, Knabe DA. Effects of diet on acidic and neutral goblet cell populations in the small intestine of early weaned pigs. Am J Vet Res. 1991; 52(10): 1743-1746, indexed in Pubmed: 1768000.

8. Forstner JF, Oliver MG, Sylvester FA. Production, structure and biologic relevance of gastrointestinal mucins. In: Guerrant RL. Infections of the Gastrointestinal Tract. Raven Press, New York 1995: 71-88.

9. Franco J, Murakami AE, Natali M, et al. Influence of delayed placement and dietary lysine levels on small intestine morphometrics and performance of broilers. Braz J Poult Sci. 2006; 8(4): 233-241, doi: 10.1590/s1516-635x2006000400006.

10. Gulbinowicz M, Berdel B, Wójcik $S$, et al. Morphometric analysis of the small intestine in wild type mice C57BL/6L - a developmental study. Folia Morphol. 2004; 63(4): 423-430, indexed in Pubmed: 15712138.

11. Habold C, Reichardt F, Foltzer-Jourdainne C, et al. Morphological changes of the rat intestinal lining in relation to body stores depletion during fasting and after refeeding. Pflugers Arch - Eur J Physiol. 2007; 455(2): 323-332, doi: 10.1007/s00424-007-0289-0, indexed in Pubmed: 17638014.

12. Hasan M, Ferguson A. Measurements of intestinal villi non-specific and ulcer-associated duodenitis-correlation between area of microdissected villus and villus epithelial cell count. J Clin Pathol. 1981; 34(10): 1181-1186, indexed in Pubmed: 7309898.

13. Higa $\mathrm{OH}$, Parra ER, Ab'Saber AM, et al. Protective effects of ascorbic acid pretreatment in a rat model of intestinal ischemia-reperfusion injury: a histomorphometric study. Clinics (Sao Paulo). 2007; 62(3): 315-320, indexed in Pubmed: 17589673.

14. Hou Y, Wang L, Ding B, et al. Dietary alpha-ketoglutarate supplementation ameliorates intestinal injury in lipopolysaccharide-challenged piglets. Amino Acids. 2010; 39(2): 555-564, doi: 10.1007/ s00726-010-0473-y, indexed in Pubmed: 20127262.

15. Hou Y, Wang L, Zhang W, et al. Protective effects of N-acetylcysteine on intestinal functions of piglets challenged with lipopolysaccharide. Amino Acids. 2012; 43(3): 1233-1242, doi: 10.1007/ s00726-011-1191-9, indexed in Pubmed: 22180025.

16. Hou Y, Wang L, Yi D, et al. N-acetylcysteine reduces inflammation in the small intestine by regulating redox, EGF and TLR4 signaling. Amino Acids. 2013; 45(3): 513-522, doi: 10.1007/s00726-0121295-x, indexed in Pubmed: 22532030.

17. Huang $X$, Zhu HM, Deng CZ, et al. Gastroesophageal reflux: the features in elderly patients. World J Gastroenterol. 1999; 5(5): 421-423, indexed in Pubmed: 11819480.

18. Kararli TT. Comparison of the gastrointestinal anatomy, physiology, and biochemistry of humans and commonly used laboratory 
animals. Biopharm Drug Dispos. 1995; 16(5): 351-380, indexed in Pubmed: 8527686.

19. Kellow JE, Borody TJ, Phillips SF, et al. Human interdigestive motility: variations in patterns from esophagus to colon. Gastroenterology. 1986; 91(2): 386-395, indexed in Pubmed: 3721125.

20. Kelly D, Smyth JA, McCracken KJ. Digestive development of the early-weaned pig. 1. Effect of continuous nutrient supply on the development of the digestive tract and on changes in digestive enzyme activity during the first week post-weaning. Br J Nutr. 1991; 65(2): 169-180, indexed in Pubmed: 1904270.

21. Kitt SJ, Miller PS, Lewis AJ. Factors affecting small intestine development in weanling pigs. Nebraska Swine Report. 2001: 33-35.

22. Laudadio V, Passantino L, Perillo A, et al. Productive performance and histological features of intestinal mucosa of broiler chickens fed different dietary protein levels. Poult Sci. 2012; 91(1): 265-270, doi: 10.3382/ps.2011-01675, indexed in Pubmed: 22184453.

23. Lieber CS. S-adenosyl-L-methionine: its role in the treatment of liver disorders. Am J Clin Nutr. 2002; 76(5): 1183S-1187S, indexed in Pubmed: 12418503.

24. Makhro AV, Mashkina AP, Solenaya OA, et al. Prenatal hyperhomocysteinemia as a model of oxidative stress of the brain. Bull Exp Biol Med. 2008; 146(1): 33-35, indexed in Pubmed: 19145343.

25. McGrath KR, Nakamoto T. Orally administered methionine alters the growth of tooth germs in newborn rats. Ann Nutr Metab. 1985; 29(6): 374-380, indexed in Pubmed: 4062248.

26. Montagne L, Piel C, Lallès JP. Effect of diet on mucin kinetics and composition: nutrition and health implications. Nutr Rev. 2004; 62(3): 105-114, indexed in Pubmed: 15098857

27. Montagne L, Pluske JR, Hampson DJ. A review of interactions between dietary fibre and the intestinal mucosa, and their consequences on digestive health in young non-ruminant animals. Anim Feed Sci Technol. 2003; 108(1-4): 95-117, doi: 10.1016/ s0377-8401(03)00163-9.

28. Nazem MN, Amanollahi $\mathrm{R}$, Tavakoli $\mathrm{H}$, et al. Effect of in ovo injected methionine on feather follicle formation and its growth in the chicken embryo. ASJ. 2015; 12: 83-88.

29. Nazem M, Kheirandish $R$, Babaei $H$, et al. Effect of short-term administration of methionine on the ovary and uterus in a rat. Comp Clin Pathol. 2017; 26(4): 867-873, doi: 10.1007/s00580017-2458-7.

30. Nazem M, Teymouri M, Jahantigh M. The histomorphometric and histopathologic effect of methionine on the epidermis and dermis layers of skin in rat. Comp Clin Pathol. 2016; 25(4): 699-704, doi: 10.1007/s00580-016-2250-0.

31. Olaibi OK, Ijomone OM, Adewole SO. Histological and Histomorphometric studies of ethanol-injured pylorus and duodenum of Wistar rats pre-treated with Moringa oliefera extract. Al Ameen J Med Sci. 2014; 7: 104-111.

32. Olaibi OK, ljomone OM, Ajibade AJ. Histomorphometric study of stomach and duodenum of aspirin treated Wistar rats. J Exp Clin Anat. 2014; 13(1): 12, doi: 10.4103/1596-2393.142923.

33. Olubuyide IO, Williamson RC, Bristol JB, et al. Goblet cell hyperplasia is a feature of the adaptive response to jejunoileal bypass in rats. Gut. 1984; 25(1): 62-68, indexed in Pubmed: 6690374.

34. Pearson JP, Brownlee IA. Structure and function of mucosal surfaces. In: Nataro JP, Cohen PS, Mobley HLT, Weiser JN, ed. Colonization of Mucosal Surfaces. ASM Press, Washington 2005: 3-16.

35. Peng YS, Evenson JK. Alleviation of methionine toxicity in young male rats fed high levels of retinol. J Nutr. 1979; 109(2): 281-290, indexed in Pubmed: 430229.

36. Sabet Sarvestani F, Rahmanifar F, Tamadon A. Histomorphometric changes of small intestine in pregnant rat. Vet Res Forum. 2015; 6(1): 69-73, indexed in Pubmed: 25992254.
37. Sakino TE, Riho KA, Michiko A, et al. Screening of toxicity biomarkers for methionine excess in rats. J Nutr. 2006; 136(6 Suppl): 1716-1721, indexed in Pubmed: 16702345.

38. Sema TK, Nevhayat TG, Nevgul DT, et al. Effects of maternal hyperhomocysteinemia induced by methionine intake on oxidative stress and apoptosis in pup rat brain. Int J Dev Neurosci. 2010; 28(4): 325-329, doi: 10.1016/j.ijdevneu.2010.02.006, indexed in Pubmed: 20188811.

39. Sharma R, Schumacher U. Morphometric analysis of intestinal mucins under different dietary conditions and gut flora in rats. Dig Dis Sci. 1995; 40(12): 2532-2539, indexed in Pubmed: 8536508.

40. Sharma R, Schumacher U, Ronaasen V, et al. Rat intestinal mucosal responses to a microbial flora and different diets. Gut. 1995; 36(2): 209-214, indexed in Pubmed: 7883219.

41. Sharp P, Villano J. The Laboratory Rat. 2nd ed. CRC Press, California 2012.

42. Smirnov A, Sklan D, Uni Z. Mucin dynamics in the chick small intestine are altered by starvation. J Nutr. 2004; 134(4): 736-742, indexed in Pubmed:15051819.

43. Specian RD, Oliver MG. Functional biology of intestinal goblet cells. Am J Physiol. 1991; 260: C183-93.

44. Swatson H, Gous R, lji P, et al. Effect of dietary protein level, amino acid balance and feeding level on growth, gastrointestinal tract, and mucosal structure of the small intestine in broiler chickens. Anim Res. 2002; 51(6): 501-515, doi: 10.1051/animres:2002038.

45. Tesseraud S, Métayer Coustard S, Collin A, et al. Role of sulfur amino acids in controlling nutrient metabolism and cell functions: implications for nutrition. Br J Nutr. 2009; 101(8): 1132-1139, doi: 10.1017/S0007114508159025, indexed in Pubmed: 19079841.

46. Thomson A, Keelan M. The development of the small intestine. Can J Physiol Pharmacol. 1986; 64(1): 13-29, doi: 10.1139/y86-003.

47. Thomson AB, Keelan M, Wild GE. Nutrients and intestinal adaptation. Clin Invest Med. 1996; 19(5): 331-345, indexed in Pubmed: 8889271.

48. Tufarelli V Desantis S, Zizza $S$, et al. Performance, gut morphology and carcass characteristics of fattening rabbits as affected by particle size of pelleted diets. Arch Anim Nutr. 2010; 64(5): 373-382, doi: 10.1080/1745039X.2010.496945, indexed in Pubmed: 21114233.

49. Ursini F, Pipicelli G. Nutritional Supplementation for Osteoarthritis. Alter Compl Ther. 2009; 15(4): 173-177, doi: 10.1089/ act.2009.15404.

50. Vaezi GH, Teshfam M, Bahodaran SH, et al. Effects of different levels of lysine on small intestinal villous morphology in starter diet of broiler chickens. Glob Vet. 2011; 7: 523-526.

51. Vahouny GV, Le T, Ifrim I, et al. Stimulation of intestinal cytokinetics and mucin turnover in rats fed wheat bran or cellulose. Am J Clin Nutr. 1985; 41(5): 895-900, indexed in Pubmed: 2986445.

52. Van Nevel CJ, Decuypere JA, Dierick NA, et al. Incorporation of galactomannans in the diet of newly weaned piglets: effect on bacteriological and some morphological characteristics of the small intestine. Arch Anim Nutr. 2005; 59(2): 123-138, doi: 10.1080/17450390512331387936, indexed in Pubmed: 16080306.

53. Viguera RM, Rojas-Castañeda J, Hernández R, et al. Histological characteristics of the intestinal mucosa of the rat during the first year of life. Lab Anim. 1999; 33(4): 393-400, doi: 10.1258/0023 67799780487814, indexed in Pubmed: 10778790.

54. Wang JX, Peng KM. Developmental morphology of the small intestine of african ostrich chicks. Poult Sci. 2008; 87(12): 2629-2635, doi:10.3382/ps.2008-00163.

55. Yao K, Yin Y, Li X, et al. Alpha-ketoglutarate inhibits glutamine degradation and enhances protein synthesis in intestinal porcine epithelial cells. Amino Acids. 2012; 42(6): 2491-2500, doi: 10.1007/ s00726-011-1060-6, indexed in Pubmed: 21861169. 